\title{
Yenidoğan bebekte Konjenital Lober Amfizem
}

Turan YILDIZ1 ${ }^{\text {, İbrahim CANER² }}$, Onur BIRCAN² ${ }^{2}$ Zekeriya ILÇE ${ }^{3}$

Öz

Yaym Bilgisi

Biz bu çalışmada solunum sıkıntısı ile başvuran beş günlük bebeğin tanı ve tedavi yaklaşımını Gönderi Tarihi:09/10/2017 sunmak istedik.

Kabul Tarihi:17/10/2017

Anahtar Kelimeler: Yenidoğan, Solunum S1kıntısı, Lober Amfizem

DOI: $10.26453 /$ otjhs. 342378

\section{Congenital Lober Amphisema in Newborn}

Turan YILDIZ1 ${ }^{1}$ i Ibrahim CANER², Onur BIRCAN², Zekeriya ILÇE ${ }^{3}$

Abstract
In this study, we aimed to present a diagnostic and therapeutic approach of five-day-old
baby who presented with respiratory distress.

Keywords: : Newborn, Respiratory distress, Lobar Amphysema
Article Info Received:09/10/2017

Accepted:17/10/2017

Online Published:31/03/2018

Corresponding Author Turan YILDIZ

DOI: $10.26453 /$ otjhs. 342378

\footnotetext{
1 İnönü Üniversitesi Tıp Fakültesi Çocuk Cerrahi AD, Malatya

${ }^{2}$ Sakarya Üniversitesi Tıp Fakültesi Pediatri AD, Sakarya

${ }^{3}$ Sakarya Üniversitesi Tıp Fakültesi Çocuk Cerrahi AD, Sakarya
}

\section{GíRIȘ}

Beş günlük bebek çocuk acil servise huzursuzluk ve beslenememe şikâyeti ile getirilmişti. Yapılan muayene sonucunda hastanın takipnesi ve solunum sıkıntısının olduğu, sağ AC de solunum seslerinin azaldığı görüldü. Hasta yenidoğan yoğun bakıma yatırıldı. Hastanın solunum sıkıntısının artması üzerine entübe edilip solunum cihazına bağlandı. Hastanın PA AC grafisi ve Toraks BT si çekildi (Resim 1, Resim 2). Tanısı konulan hastanın solunum sıkıntısı olması nedeni ile opere edildi. Sağ AC üst loba lobektomi uygulandı (Resim 3). Postoperatif 5. günde spontan soluyan hasta sorunsuz olarak taburcu edildi.

Bu hasta için tanınız nedir?

(Yanıt İçin Tıklayınız) 


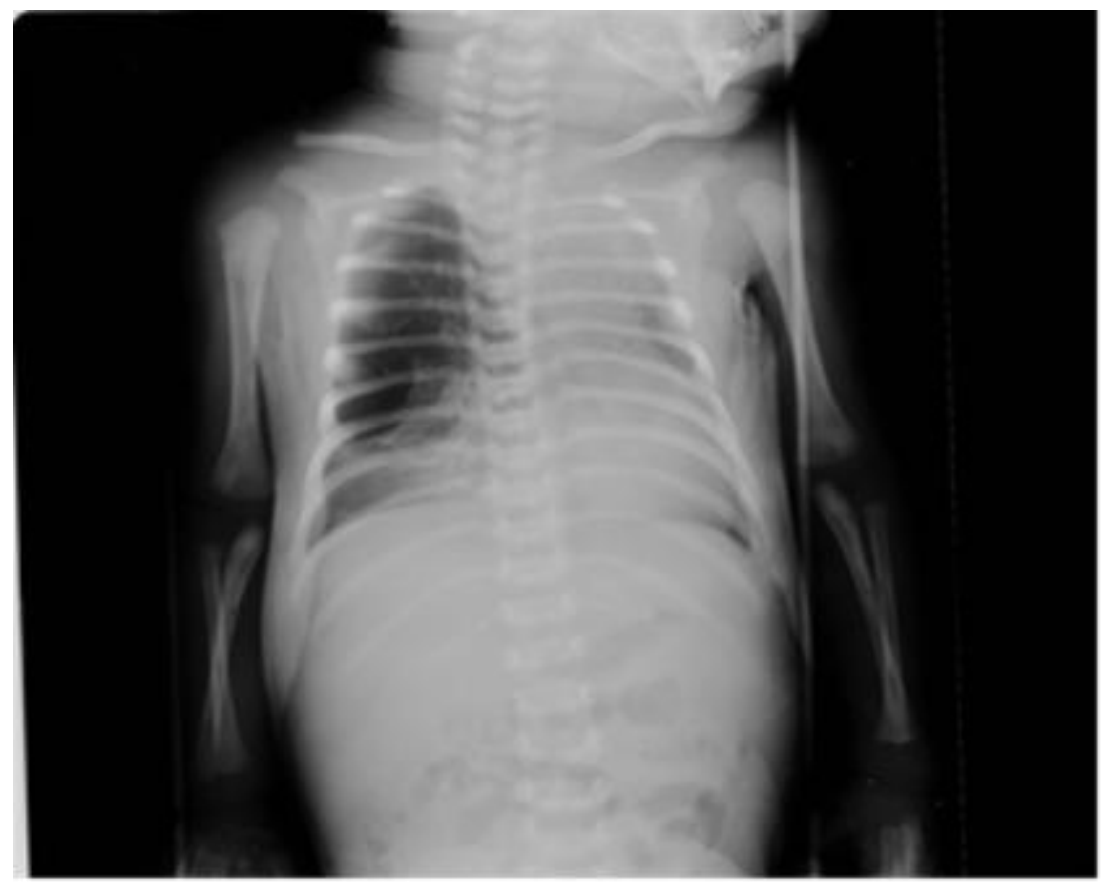

Resim 1. Hastanın PA AC grafisi

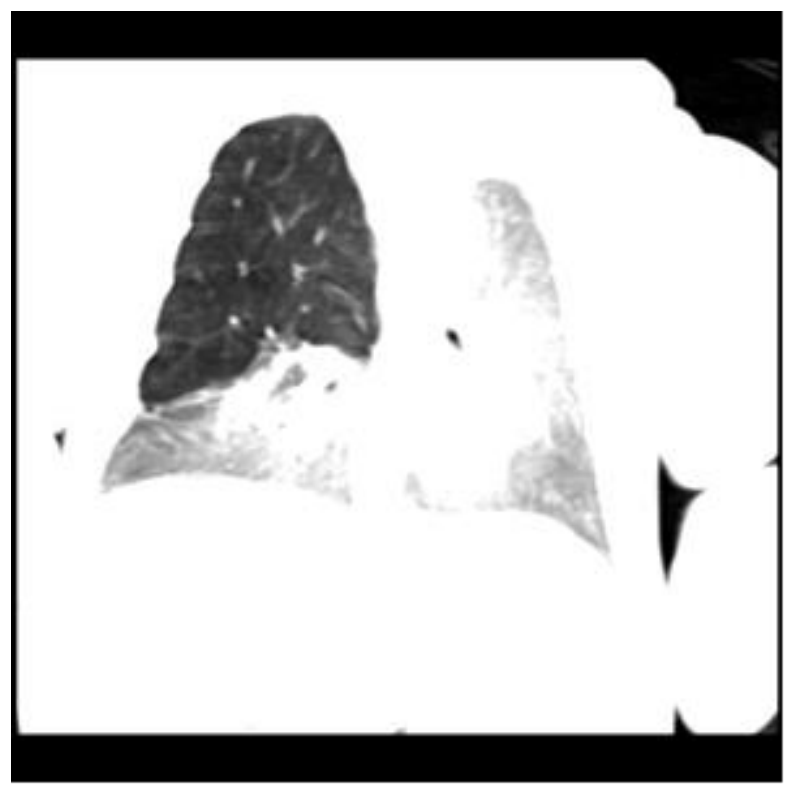

Resim 2. Hastanın Toraks BT görünümü(sagital kesit) 


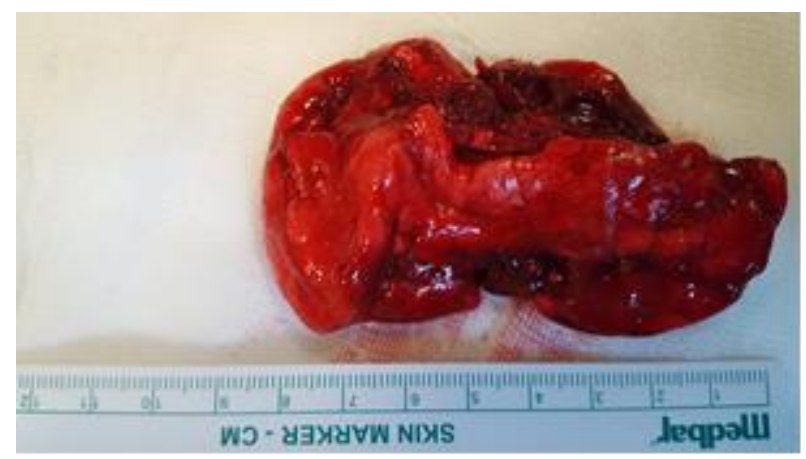

Resim 3. Lobektomi spesimeni (Sağ üst lob)

(Yanıt İçin Tıklayınız) 


\section{YANIT}

Konjenital lobar amfizem ilk defa 1954 yılında Gross ve lewis tarafından tariflenmiştir. Sıklıkla sol üst lobu tutar. Daha az olarak sağ orta ve üst lobu tutar. Alt lobları ise nadiren tutar. Etyolojisi konusunda birçok teori bulunmaktadır. En sık kabul edileni ise bronşiollerin ekstrinsik veya intrinsik sebeplerle obstriksiyonu sonucu havanın AC'e hapis olmasıdır. Erkeklerde kızlardan 3 kat daha sık görülür. Genellikle solunum sıkıntısı mevcut olup, nadiren asemptomatik olabilirler. Tanı için direkt AC grafisi, toraks BT ve MR kullanılır. Tetkikler sonucunda kosta aralıklarının arttığı, amfizem olan lobun genişleyip kalbi karşı loba doğru ittiği ve normal AC'e baskı yaparak atelektaziye neden olduğu görülür. Tedavi hastanın solunum sıkıntısına göre planlanır. Semptomatik hastalara lobektomi uygulanır. Asemptomatik hastalar ise konservatif olarak takip edilir. ${ }^{1,2}$

\section{KAYNAKLAR}

1. Barman S, Mandal KC, Kumar R, Biswas SK, Mukhopadhyay M, Mukhopadhyay B. Congenital cystic lesions of lung in the paediatric population: A 5-year single institutional study with review of literature. Afr J Paediatr Surg. 2015 Jan-Mar;12(1):6670.

2. Çeliksoy MH, Söğüt A, Sancak R, Köken Ö. Konjenital Lober Amfizem. Abant Med J. 2014; 3(3): 289-292. 